New Ideas in Psychology, 2020, Vol. 56

\title{
ELIMINATION OF BIAS IN INTROSPECTION: METHODOLOGICAL ADVANCES, REFINEMENTS, AND RECOMMENDATIONS
}

\author{
Radek Trnka ${ }^{1,2}$, Vit Smelik ${ }^{3}$ \\ ${ }^{1}$ Prague College of Psychosocial Studies, Milanska 471, 10900 Prague 10, Czech Republic \\ ${ }^{2}$ OUSHI, Palacky University, Vodarni 6, 77180 Olomouc, Czech Republic \\ ${ }^{3}$ Charles University, Faculty of Education, Magdaleny Rettigove 4, Prague 1, Czech \\ Republic
}

\begin{abstract}
Building on past constructive criticism, the present study provides further methodological development focused on the elimination of bias that may occur during first-person observation. First, various sources of errors that may accompany introspection are distinguished based on previous critical literature. Four main errors are classified, namely attentional, attributional, conceptual, and expressional error. Furthermore, methodological recommendations for the possible elimination of these errors have been determined based on the analysis and focused excerpting of introspective scientific literature. The following groups of methodological recommendations were determined: 1) a better focusing of the subject's attention to their mental processes, 2) providing suitable stimuli, and 3) the sharing of introspective experience between subjects. Furthermore, the potential of adjustments in introspective research designs for eliminating attentional, attributional, conceptual, and expressional error is discussed.
\end{abstract}

Note: This is the preprint version of the manuscript, the published article is available at https://doi.org/10.1016/j.newideapsych.2019.100753

Keywords: introspection; first-person methods; introspective methods; first-person experiments; consciousness; mental processes; self-observation; self-observer; selfawareness; bias; methods; philosophy of mind; phenomenology; Brentano; Husserl; bracketing; self; attention; memory; memory retrieval; attributions; cognitive distortions; meta-cognition; metacognition; meta-cognitive awareness; metacognitive awareness; metacognitive monitoring; metacognitive monitoring

MeSH Headings: Mental Processes; Consciousness; Self; Awareness; Cognition; Metacognition; Imagination; Attention

\section{Introduction}

Introspection is a key tool for approaching one's private mental events. The main advantage of first-person observation is that it enables direct access to one's mental life in comparison to external observations of one's behaviors. There are many areas where the methods of introspection have been successfully applied so far. Participating as both observer and subject 
within one's own psychological experiment enhances the ability to be reflexive about the given experiment, and improves the mental models of the phenomena under investigation (Corti, Reddy, Choi, \& Gillespie, 2015). Furthermore, systematic introspection helps illuminate the recollection process in memory research, because it enables one to recall and assemble conscious mental fragments from a diffuse background into coherent mental images (Weger, Wagemann, \& Meyer, 2018a).

Last, but not least, the methods of introspection are also very helpful for the scientific work itself. Systematic first-person observation enables the generation of novel hypotheses, the illumination of knowledge representation, and systematic and immanent theory building (Weger, Wagemann, \& Meyer, 2018b). In emerging scientific fields and theoretical debates, systematic introspective self-observation may bring clarity to the positions that researchers take and stimulate research-guiding insights (Weger \& Wagemann, 2015).

In recent decades, methods of introspection have been subjected to criticism (see section "Criticism of Introspection"). Some of the critical comments have been constructive, immediately calling for new methodological development in the field. However, the critical arguments relating to the methods of introspection are dispersed across different studies, and no coherent classification of biases that may occur during introspection is presently available. Elimination of various biases is of significant importance in the field of introspective methods. It may help refine the ways that allow for a clearer understanding of inner experience and contribute to a better intersubjective consensus in the psychological discourse. Also, Weger et al. (2018b) explicitly point out that a methodological cultivation is needed in the field of introspective methods. Therefore, the present study has two main goals. First, to summarize the critical arguments and to develop a general classification of biases relating to the methods of introspection. Second, to provide methodological recommendations for the possible elimination 
of bias that may occur during introspection. Finally, to discuss possible avenues for future research and theory development.

\section{Methods of introspection}

\subsection{Philosophical roots of introspection}

Introspection is the method focused on the investigation of one's own actual mental states or processes by shifting attention to them. In other words, introspection is "regarded as a process by means of which we learn about our own currently ongoing, or very recently past, mental states or processes" (Schwitzgebel, 2014). The word itself is derived from the Latin intra (into) and spectrare (to look). The engagement with one's internal flow of ideas and images has a long tradition, often standing at the heart of philosophical inquiry (Gantt \& Thayne, 2013). Philosophy, traditionally conceived as the love of wisdom, was fundamentally aimed at "knowing thyself", and thus the process of introspection was considered as very helpful in this quest.

Many philosophical positions considering to a greater or lesser degree the introspective access to one's own actual mental processes have emerged during the past centuries. To provide a comprehensive overview of all philosophical perspectives focused on introspection is far beyond the scope of the present study (but see, e.g. Schwitzgebel, 2014). Therefore, the following outline is selective and primarily aimed to introduce some of Brentano's and Husserl's thought that was influential for the later development of recent methods of introspection.

Brentano was one of the first who considered mental phenomena as something genuine and independent of the physical realm, that is influenced by a deterministic causality. He argues 
that the consciousness of something occurs together with the subjective awareness of one's mental act (Brentano, 1995). By accepting this, his thought had important consequences for the possibility of considering introspective reporting as a valid research tool. Brentano's contribution to the later utilization of first-person methods in psychology is very significant, as Brentano conceptualizes the introspective experience on a psychological basis, i.e. as an intentional act independent of any intersubjective agreement (Brentano, 1995). According to this position, intentionality is an intrinsic feature of the psyche (inner life), the mere faculty of being directed toward "some objects or states".

The dualistic position of Brentano helps him defend the autonomy of mental phenomena. Mental phenomena are considered to be distinct from physical phenomena, and are thus available for scientific scrutiny. Brentano's position avoided the risk of monistic indifference, and supported the validity of first-person reporting, i.e. the meaningfulness of the first-person description of one's own mental processes, in scientific research. Physical phenomena are suggested to exist only through the evidence of the mental phenomena that correspond to the physical ones.

The dichotomy between mental and physical phenomena was later criticized by Husserl. According to Husserl (1970), Brentano's thought remains dualistic and bound to the prejudices of the naturalistic tradition. Husserl (1977) seeks to ground knowledge on a more profound (non-dualistic) and universal basis. He does so by justifying the existence of the universal essences of things. Such hypothesized essences are neither abstract nor psychologically "certain", as in Brentano's case. The hypothesized essences may represent points of reference or suitable anchors on the path of introspecting our inner life. This way, Husserl tries to avoid the rather particular and exclusively psychological consequences of Brentano's approach. He believes that an intersubjective agreement can, indeed, be reached, and also that introspection relies on learning. 
Husserl (1977) was also not satisfied with the way in which Kant (1999) explained "the way we are conscious of phenomena", since it entails the division of the world between things-inthemselves and appearances. Things-in-themselves are meant to be essences or ideals of the things we experience; appearances are considered the actual phenomena we experience (Kant, 1999). Husserl (1983) attempts to overcome the dichotomy between them. The thing-in-itself and phenomenon are intertwined, and the interaction between them can be captured through the method of "bracketing", i.e. looking at things from a distance. In doing so, we can capture subjective experience without necessarily imposing its "worldly" objective counterpart, and are thus free from the prejudices this "objective world" entails. Husserl (1983) makes room for unique introspective and actual experience, purified of all kinds of biases. To do so, one has to learn "to see" without presuppositions. Husserl (1983) understands this way of self-observation, which does not adhere either to the objective world or to the subject-idealist experience, as the phenomenal.

As for introspection, Gutland (2018) assesses Husserl's contribution in the following way: "This is relevant for introspection insofar as there is a crucial distinction between what is happening in consciousness and what we notice about it. The Husserlian epoché is a means of becoming aware of conscious processes that usually go by unnoticed. Therefore, if you practice epoché, it is not that you genuinely create the aspects of consciousness you become aware of, but rather you shift your attention toward them." (p. 5). Recently, Weger, Meyer, and Wegemman (2016) hold that consciousness is defined as a flow of mental contents independent of human will, but awareness is considered to be a major device of introspection. Via introspection, we shift our attention to selected features of consciousness. Weger et al. (2016) propose that the method of introspection should be described as clearly as possible in order to make first-person research fully transparent. 


\subsection{Introspection and self-awareness}

Accessing one's own mental states in introspective research is closely related to the process of self-awareness. Self-awareness refers to a subject's capacity to become the object of their own attention (Morin, 2006). A long tradition of first-person experience, going back to Hume, indicates that a subject can attend to their mental states, mental processes, mental contents, etc., although it cannot find an inner subject of experience, e.g. an inner subjective entity (Peacocke, 2014). Self-awareness occurs when one's attention focuses consciously on the internal milieu. In phenomenological terms, it is a process of becoming aware or noticing what one experiences (Ziegler \& Weger, 2018b). Self-awareness is thus considered a second-order state either in the domain of experience or in the domain of thought (Werning, 2010).

Through self-awareness, a subject may acquire either conceptual or perceptual selfinformation. This distinction may not always be sharp in different instances of mental processes (Werning, 2010), but generally, perceptual self-information refers to mental contents that emerge in relation to and are closely interconnected with sensory inputs, i.e. what a subject perceives through the basic human sensory organs, that is, through sight, sound, taste, smell, and touch. In contrast, conceptual self-information is suggested to be related to a greater extent to one's externally non-observable events and characteristics such as emotions, physiological sensations, values, goals, motives, etc. Morin (2006) uses the term private self-information to capture this realm of processes (Figure 1). Interestingly, some emotions are expected to have both conceptual and perceptual aspects (Werning, 2010). Aside from private self-information, there is also self-related information involving family, work, health, and future (Figure 1).

Several features of the quality of self-awareness and introspective access can be observed. Morin (2006) distinguishes the frequency of self-observation (the time spent by observing the 
self), the amount (or accessibility) of self-related information, and the accuracy of selfknowledge.

Questienne, van Dijck, and Gevers (2018) distinguish three qualitative characteristics of introspective reports: sensitivity, specificity, and validity. Sensitivity refers to a subject's ability to introspectively report subtle modulations of experience, e.g. in the case of experiment of Questienne, van Dijck, and Gevers (2018), the ability to introspectively report the subjective experience of response conflict when the participants were asked to report a subjective urge to make an error in the experimental task involving the recognition of the colors of blue, yellow, red, or green rectangles. Furthermore, specificity refers to a subject's ability to dissociate different aspects of inner experience, and validity to the degree with which a subject introspectively approaches the inner mental processes. All of these features are important to consider when analyzing the results of introspective reporting.

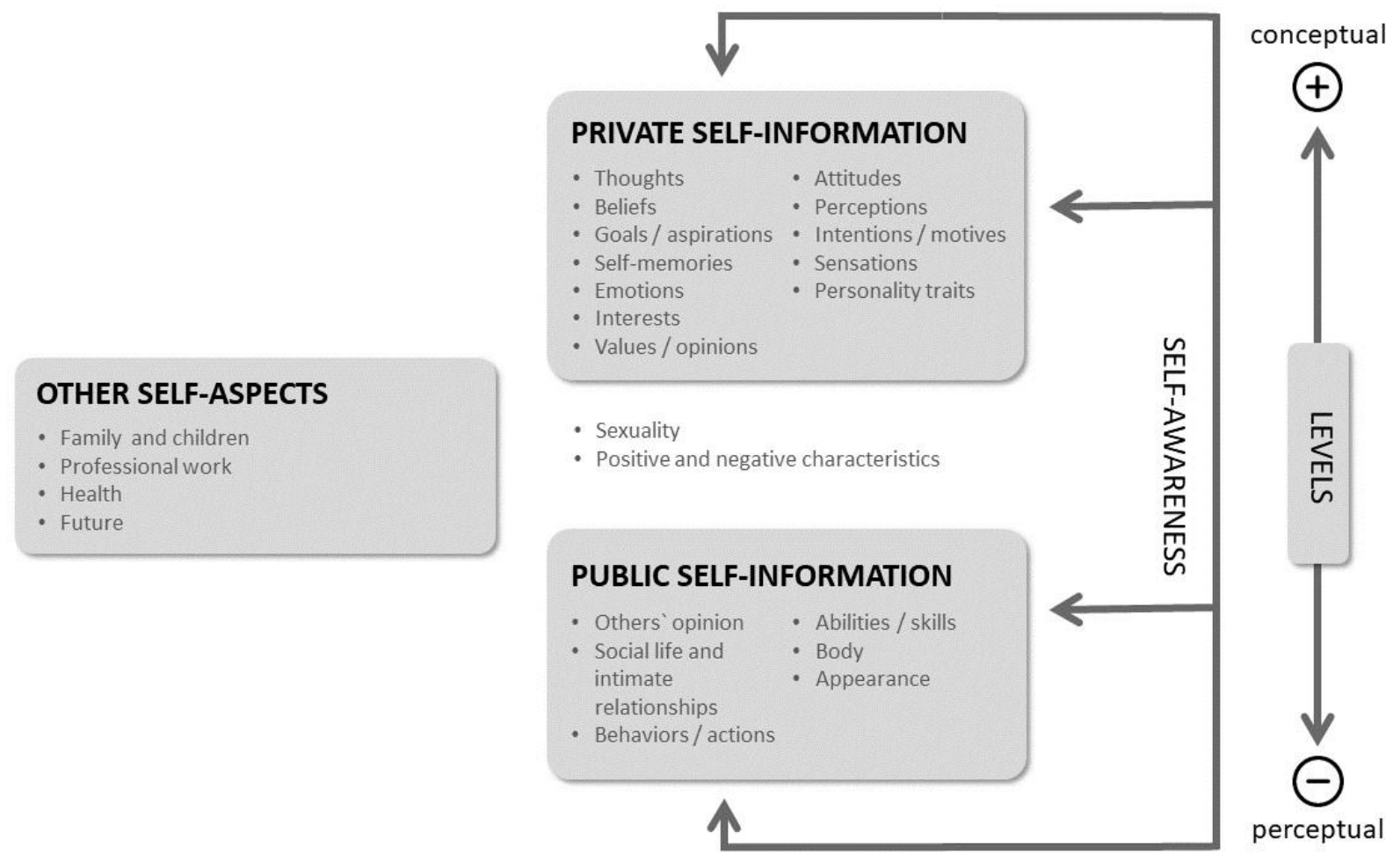

Figure 1. Model of conceptual and perceptual self-information and levels of selfawareness (Adapted from: Morin, 2006) 


\subsection{Empirical research using introspection}

Methods of introspection have been used in both first-person and third-person research. The distinction between these two streams of research is founded on the different position of the observer in the research design. First-person research uses direct self-observation as a principal method (Weger et al., 2018a). During the first-person approach, the subject participates as both an observer and a participant within one's own psychological experiment.

In contrast, third-person research utilizes an external observer's point of view. Third-person methods, sometimes also called second-person methods (however, the term third-person methods will be used further in the text, as it is more widely used), are methods based on distanced measurement. Simply put, the subject, e.g. participant of an experiment, is different than the observer, e.g. researcher, who observes from a distanced, third-person perspective. Third-person methods can be used for the investigation of, for example, the content of naturally occurring inner experience (e.g. Heavey \& Hurlburt, 2008). The participants are instructed to recall and immediately note all the details of their inner experience at randomly selected moments during the day. Later, during an interview with an external researcher, the participants are asked about the details of their past experience at each sampled moment.

In the field of first-person research, methods of introspection have been used for the investigation of various mental processes, such as imagining a circular object in one's mind (Ziegler \& Weger, 2018a), of volitionally controlled perceptual reversals (Wagemann, Edelhäuser, \& Weger, 2018), of recollection from memory (Weger et al., 2018a), and of mind wandering (Weger et al., 2018b). Furthermore, third-person research uses introspection for the investigation of the content of inner speech (Morin, Duhnych, \& Racy, 2018), of the frequency of inner speech (Ren, Wang, \& Jarrold, 2016), of the frequency of self-talk (Brinthaupt, Benson, Kang, \& More, 2015), of the content of naturally occurring inner experience (e.g. Heavey \& 
Hurlburt, 2008), of the awareness of mind-wandering and mind-blanking (Bastian et al., 2017; Ward \& Wegner, 2013), of the possibility of reporting phenomenal experience (Questienne et al., 2018), of experiences during meditation (Przyrembel \& Singer, 2018), or of the ex post retrieval of the reasons for making a certain decision (e.g. Nisbett \& Wilson, 1977; Petitmengin, Remillieux, Cahour, \& Carter-Thomas, 2013).

First-person and third-person research using the methods of introspection has a great potential for informing each other. There is also a potential area for conducting novel research that would combine both methodological approaches.

\subsection{Criticism of introspection}

Methods of introspection have been criticized from various positions (for an overview, see Hurlburt \& Heavey, 2001; Peels, 2016; Ramm, 2018). For example, Dennett (2003, 2007) claims that the first-person science of consciousness is a discipline with no methods, and considers the making of judgments about one's own experience to be unscientific. A significant part of past criticism is quite general, i.e. following the behaviorists' position by accepting only externally detectable, verifiable, and methodologically testable aspects of cognition (see Clegg, 2013). In other words, the reliability of the cognition of inner experience was considered to be limited compared to the cognition of external events. This general criticism served as an important starting point for distinguishing the specific errors that may occur during introspection (see later subsections).

Interestingly, some recent scholars also follow this line of criticism. The persistent presence of bias is suggested to be present in subjective measures and in all introspective methods (Irvine, 2012). Subjects are suggested to be incapable of controlling their own self-distorting biases (Piccinini, 2010) and only the external experimenter is suggested to validly use a subject's reports as data (Dennett, 2003, 2007). 
An important source of criticism has crystallized among introspectionists themselves during the debate on the nature of "imageless thought" (Hurlburt \& Heavey, 2001). In contrast to sensationalism, i.e. the assumption that thinking without images is impossible (Titchener, 1980), several German introspectionists suggest that some ideas are not at all of imaginal nature, labeling them as "imageless thought". This controversy related to the basic nature of introspection contributes to the skepticism concerning methods of introspection. Recently, some third-person empirical studies suggest that non-symbolic thinking may occur when investigating naturally occurring inner experience (e.g. Heavey \& Hurlburt, 2008).

\subsubsection{Attentional and conceptual errors}

When searching for more concrete insights into the bias accompanying introspection, Ramm (2018) provides a general classification of two errors accompanying introspection, namely attentional and conceptual error. Attentional error occurs when the subject fails to notice the target experience due to a lack of attention. In contrast, conceptual error occurs when the subject makes an incorrect judgment about the target experience because of a failure in possessing, forming, or employing the correct concept about the experience (see also Clegg, 2013). For example, when a subject experiences a highly complex emotional experience, it may be sometimes difficult to access the correct concept about such an experience. Human emotional life shows a very high variability. Therefore, some instances of complex emotional experience may be relatively new or uncommon for a subject. Under these circumstances, it may be problematic for a subject to connect the target experience with the relevant concepts of emotions formed during past emotional situations. 


\subsubsection{Expressional error}

A reliable awareness of inner experiences and its expression in words, i.e. in natural language, is sometimes very difficult for subjects to achieve. Already Skinner (1953) identifies the verbal difficulties related to reporting inner experience to be one of the limitations of the scientific use of first-person methods. The problem with reporting inner experience is that many of our inner experiences have the character of non-symbolic thinking, i.e. they are the experience of thinking without words or other symbols (Heavey \& Hurlburt, 2008). Werning (2010) suggests that not all mental processes are easily accessible through introspective reporting, or can be properly expressed by natural language. Only mental processes that have a phonological or quasi-phonological structure, e.g. a sub-symbolically structured inner speech, are suggested to be available for reliable introspective reporting (Werning, 2010). However, the targeting of the researchers' attention to inner speech also cannot ensure the optimal reliability of introspective reporting. Knappik (2017) points out that inner speech is normally highly fragmentary and condensed, and that it is problematic for subjects to express the stream of their inner speech in words.

\subsubsection{Attributional error}

Third-person research of memory retrieval has shown that subjects may fail when retrieving the causes of their previous behaviors. The reliability of introspective reporting has shown to be low when subjects try to retrieve the reasons for their past decisions (Nisbett \& Wilson, 1977). Indeed, conscious or intentional memory retrieval may be slightly too problematic to be considered an introspective process, because, according to Schwitzgebel's definition (2014), introspection is suggested to be a judgment about one's current or very recent conscious experiences. However, we mention the instance of attributional error here to provide the reader with a comprehensive outline. 
Previous research showed that introspective memory retrieval can easily be influenced and even deceived by the transformation of memory across time (Clegg, 2013) or by external psychological manipulation (Weger \& Wagemann, 2015). Jopling (2011) also points out the difficulty of participants to ascribe reasons to their previous behaviors. During introspective memory retrieval, disturbances such as confabulation or rationalization are suggested to occur. Despite of the criticism focused on attributional bias during introspective memory retrieval, some research shows that attributional error occurs only during some types of mental acts. Petitmengin et al. (2013) show that specific mental acts enable good access to the correct attribution of the causes of the previous decisions of subjects. Reyes and Sackur (2018) point out that the low reliability of introspective memory retrieval may be a by-product of an inadequate experimentation context. Generally, attributional error is suggested to occur only in the inquiry involving an ex post explanation of previous behaviors.

In sum, four main errors may occur during introspection: attentional error, attributional error, conceptual error, and expressional error (Table 1). This classification will be used in the following sections throughout the present study. 
Table 1. Classification of main errors that may occur during introspection.

\begin{tabular}{ll}
\hline Error type $\quad$ Description \\
\hline
\end{tabular}

Attentional Subject fails to notice the target experience due to a lack of attention error

Attributional Subject fails to explain the causes of their previous behaviors error

Conceptual Subject fails to access the particular concept of the target experience error

Expressional Subject fails to reliably express the target experience in natural error language because of the verbal difficulties related to reporting subjective experience

\section{Possible ways of eliminating bias in introspection}

In order to discover the possible ways of eliminating the errors mentioned above, the authors conducted a search and a focused excerpting of scientific literature related to the methods of introspection. The analysis of introspective literature was targeted on finding possible ways of eliminating the errors that may occur during introspection. The analysis was not restricted either to first-person or to third-person research. Both streams of introspective research were used as possible resources of ideas leading to the improvement of the reliability of introspective research. The following groups of methodological recommendations were determined: a better focusing of the subject's attention to their mental processes, providing suitable stimuli, and the sharing of introspective experience between subjects. These groups were not created using a predetermined conceptual framework, but were allowed to emerge from the focused excerpting 
of scientific literature in the course of analysis. The main insights within each group of methodological recommendations are presented in the following sections.

\subsection{Focusing of the subject's attention to mental processes}

\subsubsection{Motivating the subject to focus attention on their mental processes}

The motivation of the subject to focus attention on their mental processes is considered to be essential for the good accessibility to mental processes. Brinthaupt et al. (2015) highlight the important role of motivation in recognizing or acknowledging one's self-talk. It can be assumed that subjects who are highly motivated to observe their inner experience report more utterances and details about their inner experience.

The third-person experiment of Zedelius, Broadway, and Schooler (2015) shows that being motivated to monitor and catch oneself when their mind is wandering enhances the introspective access to spontaneous, task-unrelated thoughts. Subjects were motivated by incentives such as the opportunity to gain a monetary bonus for accurate reporting or for calculating their overall bonus, i.e. to receive a point for each accurate self-report and lose a point for each inaccurate self-report of mind wandering. The authors controlled the validity of self-reports by the covert behavioral assessment of mind wandering. The results showed that motivated subjects showed a higher accuracy in catching themselves if their mind wandered. Motivating subjects is thus a good way to enhance attention to subjective mental processes in third-person introspective research. In first-person experiments, the subjects under investigation are the researchers themselves, so one may expect that they can be motivated by the fact that they are doing their own research projects. 


\subsubsection{Training of the subject's introspective competencies}

The systematic training of introspective competencies has been revealed to be an effective way of improving introspection. Weger et al. (2016) demonstrate how such training improves first-person access to one's mental processes. They implemented five exercises based on meditative concentration. During 10-15 minute inner observation trials, the subjects concentrated on concrete shapes (a triangle) or words. By repeating these exercises, the accessibility of inner experience was improved. For example, when concentrating on a triangle, subjects achieved better introspective insights into the structural laws of the triangle, despite of the fact that the subjects did not observe any concrete physical picture of a triangle. In a similar vein, subjects may be trained in various introspective focuses. This kind of training has great potential for the elimination of conceptual error in introspection, i.e. when the subject fails to properly access the appropriate concept.

\subsubsection{Bracketing presuppositions}

The failure of the explanations of the causes of one's previous behaviors is often related to the subjects' use of generalizations, rationalizations, confabulations, or other kinds of cognitive distortions in the ex post attributions of causes (see Khalil, 2017). Jopling (2011) points out that subjects often provide readily available generalizations about themselves when they are confronted with after-the-fact cause-seeking introspective questions such as "Why did I do that?". These generalizations may be based on culturally-learned and idiosyncratic theories about "why I performed behavior X" (Jopling, 2011) or on other cognitive distortions.

To eliminate this bias in the introspective ex post explanation of a subject's previous behavior is not easy. Some researchers recommend the bracketing of presuppositions or the bracketing (suspension) of everyday belief-constructs as a necessity at all levels of introspective investigation (e.g. Hurlburt, 2018; Wagemann, Edelhäuser, \& Weger, 2018). Despite of the fact 
that many phenomenological philosophers have used the bracketing of presuppositions with success, the question is how to implement the bracketing of presuppositions in introspective empirical research in psychology. The bracketing of presuppositions should enable the subject to be minimally influenced by their intentions, motives, values, attitudes, and opinions when observing their inner processes. On the other hand, it is difficult to imagine how to instruct the participants to bracket their presuppositions, i.e. to temporarily remove their intentions, motives, values, attitudes, and opinions from their consciousness. The development of research designs enabling subjects to fully control the influences of intentions, motives, values, attitudes, and opinions during introspection is a big challenge for the future methodological developments in the field.

At the same time, Ziegler and Weger (2018b) point out the differences in the effort that needs to be exerted in different instances of introspective access. Introspecting senseperceptions, e.g. the mental images of geometric concepts, is suggested to be relatively easy in comparison to the focused production of conceptual thinking. This type of introspection aims to approach the material that is not available to one's consciousness without one's active effort and involvement. The focused production of conceptual thinking is necessary, for example, when approaching conceptual relations, i.e. the relations between lines, points, and circles in the case of geometric concepts (Ziegler and Weger, 2018b).

\subsection{Providing suitable stimuli}

The first-person experiments of the subjective experience of contours show that the appearance of contours is significantly shaped by changes in the spatial organization of patterns, even in the case when the stimuli shapes are the same (Ramm, 2018). The changes in the spatial organization of black pie-shapes elicit an emergent phenomenal character of experience of 
visual stimuli, i.e. the experience that one sees an illusory triangle. Ramm (2018) points out that the appropriate phenomenal concept can be activated or formed by providing suitable stimuli. In this case, the suitable stimuli eliminated the likelihood of possible conceptual errors in the experimental settings, where no actual closed triangular figures were present in the stimuli and the induced experience of a triangle was only illusory.

Reyes and Sackur (2018) show that more suitable modifications of experimental conditions can improve the introspective access to one's mental content in the case of using identical stimuli. Many previous studies use perceptually different stimuli to generate different cognitive processes of introspection. However, this negatively influences the participants' subjective reports, which had the character of interpretative, confabulatory reports rather than truly introspective reports (Reyes \& Sackur, 2018). Through the suitable modification of experimental manipulation, the authors suggest that the participants' reporting approached even highly complex cognitive processes, such as decision making.

Furthermore, Morin (2006) points out that people who are frequently exposed to environmental stimuli that remind them of their objective status for others tend to also show higher levels of self-awareness when compared to those individuals who are not. This kind of stimuli conditions includes, for example, self-focusing stimuli, such as mirrors, audiences, or video recordings of the self. The self-focusing stimuli could be utilized in experiments in various ways, e.g. as primes, as experimental stimuli that are present during a subject's introspection, or as stimuli for training introspective access before an experiment. Such types of stimuli conditions may stimulate higher levels of self-awareness. However, it is questionable whether higher levels of self-awareness may also lead to a higher engagement in selfobservation and to deeper introspective insights. 


\subsection{The sharing of introspective experience between subjects}

The sharing of experiences between subjects may help increase the validity of introspective reporting, since intersubjective consensus can ensure that all subjects are speaking about the same thing (Weger \& Wagemann, 2015). Telephone conferences, personal meetings, or online discussions are considered to be examples of tools that can be used for the intersubjective sharing of introspective insights (e.g. Weger et al., 2018b). Such sharing of one's first-person experience is suggested to be able to prevent the unexpected and involuntary biases that may arise from different expectations and prejudices (Ziegler \& Weger 2018a). The mutual reporting of experiences enables the mutual influencing, sharpening, and mirroring of individual selfobservations (Weger, Meyer, \& Wagemann, 2016). Intersubjective consensus and sharing are suggested to be very helpful for the elimination of expressional errors that may arise from the difficulty of reliably expressing the description of mental processes using natural language. Sharing inner experiences between subjects can help a subject find the expressions and words that can satisfactorily describe the particular inner experience. The experimenters may also guide or specifically instruct the subject before an experiment to avoid expressional errors and to achieve more reliable introspective reports. Within the quantitative third-person designs, the ex post validation of responses across a sample can be conducted as well. Comparing the responses of different subjects in order to validate each separate response may eliminate the expressional errors of individual subjects, but such comparison cannot help us avoid any errors arising from the generalization across the sample as a whole.

Finally, it is also important to stress that the sharing of experiences between subjects may be vulnerable to group biases and errors arising from the post-event consolidation of primary introspective reports. To correct and consolidate one's own first-person description of the inner experience also implies that one's description is being confronted with an outside source of 
information. Such post-event exposition to new information from a different subject or subjects may bias the primary introspective report. This so-called misinformation effect (Pickrell, Bernstein, \& Loftus, 2012) occurs when a person's description of past experience becomes less accurate because of being later exposed to new information. The new information that a person later receives is suggested to work backwards in time, and distorts the primary memory of the original event or experience. Therefore, the misinformation effect should be taken into account when planning research designs involving the ex post sharing of experiences between subjects.

\section{Discussion}

The previous criticism has revealed four main errors that may occur during introspection, attentional, attributional, conceptual, and expressional error. When looking at the essence of these errors, all of these errors may occur not only during first-person introspection, but during introspection of any kind. This implies that errors reported in previous critical studies are not specific to first-person introspective inquiry, but may be expected to occur in all research that focuses on the exploration of mental processes.

\subsection{Future research and research gaps directly observable from the errors}

\subsubsection{Elimination of attentional, attributional, conceptual, and expressional errors}

The present study raises several methodological issues to be discussed. Attentional error refers to the instance when a subject fails to notice the target experience because of a lack of attention focused on this target experience. The present study brings several methodological recommendations for the elimination of attentional error, i.e. focusing the subject's attention on inner mental processes, or providing a stimuli that can enhance the subject's attention during 
introspection. Despite of these methodological recommendations, there is a lack of empirical evidence, especially in the fields such as the evaluation of the effectiveness of focusing a subject's attention on their mental processes, the comparison of a group stimulated within an experiment with the control group of participants, within which there is no stimulation of a subject's attention towards their mental processes, and the comparison of the impact of various stimuli on the quality of a subject's attention during introspection.

In contrast, conceptual error denotes a problem in accessing the subject's concept of the target experience. This kind of problem can be considered a threat for reliable introspective reporting. If a subject does not access the particular concept of the target experience, their introspective reporting may be less reliable. Here, the training of the subject's introspective competencies is one of the most promising ways of improving a subject's access to conceptual knowledge. Previous research has revealed that the systematic training of introspective competencies succeeds in improving first-person access to one's own mental processes (Weger et al., 2016). On the other hand, it has not been recently clear how introspective reporting may be biased by the specific styles of training introspective competencies. There are various ways of training introspective competencies, and the empirical evidence is sparse in this field. However, it can be hypothesized that the specific training approaches and procedures may also have specific impacts on the first-person access to one's own mental processes. More research comparing different approaches for training introspective competencies is needed in this field.

Similarly, it is not known how the sharing of introspective experience between subjects may be biased by the selection of subjects for the study. Human minds are highly complex systems, comprised of various intentions, motives, values, attitudes, and opinions. The sharing of introspective experience between subjects in first-person research designs denotes the interaction between the minds of a relatively low number of subjects. Therefore, one may ask 
if and how the results of first-person inquiry may be influenced or biased by the specific patterns of intentions, motives, values, attitudes, and opinions.

When thinking about the sources of expressional error, i.e. the subject's problematic expression of inner processes, two possible sources of this error can be considered. First, the problematic expression can be related to the aforementioned problematic access to subject's concept of the target experience. Here, the subject's problematic access to conceptual knowledge may also influence the use of language during introspective reporting. Second, problematic verbal expression can be also influenced by the subject's limited language competencies, i.e. not all subjects have the same vocabulary, stylistic competencies, or storytelling talent. Despite of good access to concepts about the target experience, the subject is not assured they are able to express it reliably in natural language.

There is no doubt that language competencies influence the quality of introspective reporting. The solution could be to select participants with good language competencies or to train subjects in improving their language competencies before their participation in the study. However, the question is how such training of language competencies should be designed to be effective, and, at the same time, not influence introspective reporting inappropriately. One may even question if the training of subjects in psychological or philosophical terms and concepts is a good method at all. By familiarizing subjects with scientific terminology, introspective reporting may become more rich and detailed, but at the same time, it can also become biased in terms of influencing the subjects' language competencies for the purpose of the research itself. This effect should be considered when planning future introspective research designs, as well as when interpreting the data from introspective studies using professional scientists as participants.

Finally, the present focused excerpting of scientific literature did not reveal any methodological recommendations for the elimination of attributional error. Attributional error 
may occur during introspective memory retrieval of reasons for a subject's previous decisions or behaviors (Clegg, 2013; Nisbett \& Wilson, 1977; Weger \& Wagemann, 2015). Future research in this field should focus on an in-depth exploration of the process of attributing reasons for a subject's previous decisions or behaviors. This research should also explore the alternative possibilities of explanations of a subject's previous decisions or behaviors, which may bring new insights into the selection process of reasons from possibilities as a whole.

\subsubsection{Self-absorption and attention during introspection}

Attentional activity is needed when a subject aims to observe their inner mental processes. However, the question remains, how does the attentional activity itself influence the introspective process? When one tries to introspect on their inner experience, they may feel the lack of the cognitive capacity to do so, since their attention may be fully absorbed in a given experience (Ziegler \& Weger, 2018a). Thinking about what one experiences may thus absorb some part of the subject's attention. One may even speculate that the experience of introspection may alter the original experience, because such an effort may elicit a change in the introspective process, allowing a kind of experience that did not previously exist to emerge. A possible hypothesis that draws from Husserl's concept of epoché could be that by distancing one's self from experience, one does not alter it, but merely lets it be and stands beside it.

\subsubsection{Self-observer effect}

Already Brentano (1995) distinguishes between inner observation and inner perception. Inner observation is suggested to involve full attention to one's mental processes and interferes with the process of observing (Schwitzgebel, 2014). In contrast, inner perception is suggested not to involve attention to one's mental processes. 
More recently, Ziegler and Weger (2018a) mention an important dilemma involving the effect of self-observation in itself. They point out that a subject cannot be sure if their experience is disturbed by their self-observation or not. Or, in the case that it is, to what extent? A subject is an active agent of self-observation during introspection (Brinkmann, 2013). Any observer, however, unearths processes that have always been implicitly present. It is true that an observer creates a quality formerly not present, but it would be an exaggeration to say that they themselves invent it. Current scientific knowledge about the human cognitive capacities for the reflexive processing of the effects of self-observation on the quality of introspective reporting is limited. Therefore, an investigation of the quality of a subject's self-awareness of the process of self-observation may pose an interesting challenge for future research.

\subsubsection{Controlling self-serving bias}

The reliability of self-related information reported in introspective research may be influenced by cognitive self-distortions that help subjects protect their self-esteem (Morin, 2006). Subjects are often engaged in a wide variety of self-serving bias, e.g. self-enhancement, self-inflation, and overly positive self-views (Clegg, 2013; Kurt \& Paulhus, 2008; Kwan, John, Robins, \& Kuang, 2008). This self-distorting cognitive bias may elicit attributional, conceptual, as well as expressional error in introspective reporting, because subjects tend to report their subjective experience unreliably in an effort to protect their self-esteem. The introspective reporting of private self-information is then distorted by this bias. Any future research seeking the methods of controlling these types of self-serving biases should be aware of the sensitive nature of this bias and of the adaptive character of a subject's need to protect their self-esteem. It is also necessary to mention the ethical issues of retrieving self-related information protecting self-esteem. One may ask if the retrieval of such material is safe for a subject, and whether it could cause any negative mental health outcomes or discomfort for the subject. 


\subsection{Future research and research gaps regarding the wider framework}

\subsubsection{In-depth exploration of language used during introspective reporting}

Future research should pay increased attention to the language that subjects use for their descriptions of inner experiences (see Wagoner, 2013 for further insights). For example, Kross et al. (2014) investigate the influence of the language that people use to refer to the self during introspection. Interestingly, using non-first-person pronouns and one's own name enhanced self-distancing during introspection (Kross et al., 2014). Self-distancing may generally be valued as enhancing the objectivity of research. Despite of the need for objectivity and especially for the intersubjective sharing of results, the question remains if and to what extent should participants accommodate their language to be more similar to the language that is used in psychological theory and research? Is this desirable? Or vice versa, can we expect that scientific language should be inspired by the introspective reports of the "naive" participant? Should scientific language be influenced by the language used by the participant who is not simultaneously in the role of the researcher? These questions underlie the need for the sensitive analysis of the language that is used during introspective reporting (compare also narrative versus metacognitive introspection in Gould, 2013), and also for future discussions relating to the interactions between the language of researchers and the language of participants.

\subsubsection{The role of background during introspection}

Any intention of observing one's inner experience needs a background against which it only gains meaning, i.e. preceding thoughts, perceptions, feelings, or imaginations. Every determination requires a field of possibilities from which such a determination can be formed. Every focusing of attention excludes some of the other possible perspectives, as well as 
presupposes a number of backgrounds. The act of introspection requires a background from which it originates, and we may therefore ask what role does this background play during introspection? Or, how may the background influence such introspective reporting? Future theoretical development should discuss how the results of introspection are interrelated to the background of one's cognition that is present before and during introspection.

\subsubsection{The influence of the interviewer/analyst}

Within third-person introspective inquiry, the interviewer or analyst plays an important role for the obtained results. Especially in the case of qualitative interviewing, the interviewer always interacts with the participant and this interaction also shapes the subsequent development of the interview and of the yielded results. Therefore, the influence of the interviewer, as well as the analyst, should be taken into account when evaluating the validity of introspective reports in third-person research.

\section{Conclusion}

In the present study, the past constructive criticism of the methods of introspection has been summarized and analyzed. The biases and distortions accompanying introspection are a necessary by-product of a subject's cognition. Considering these critical arguments together results in the classification of four main errors that may occur during introspection: attentional, attributional, conceptual, and expressional error. Furthermore, the following methodological recommendations for the possible elimination of these errors have been determined: 1) a better focusing of a subject's attention to their mental processes, 2) providing suitable stimuli, and 3) the sharing of introspective experience between subjects. However, we have shown that it is not possible to reliably estimate the extent to which the errors that may occur during 
introspection can be eliminated or regulated. This, in turn, opens new avenues for future research, which this paper was able to point out.

\section{Acknowledgments}

This work was supported by the Palacky University Olomouc Institutional Support of Research Organizations - CMTF (I-2018).

\section{References}

Bastian, M., Lerique, S., Adam, V., Franklin, M. S., Schooler, J. W., \& Sackur, J. (2017).

Language facilitates introspection: Verbal mind-wandering has privileged access to consciousness. Consciousness and Cognition, 49, 86-97.

Brentano, B. (1995). Psychology from an empirical standpoint. London, England: Routledge.

Brinkmann, S. (2013). The practice of self-observation in the phenomenological traditions. In J. W. Clegg (Ed.), Self-observation in the social sciences (pp. 195-219). New Brunswick: Transaction Publishers.

Brinthaupt, T. M., Benson, S. A., Kang, M., \& Moore, Z. D. (2015). Assessing the accuracy of self-reported self-talk. Frontiers in Psychology, 6, 570.

Clegg, J. W. (2013). Developing an adequate theory of self-observation. In J. W. Clegg (Ed.), Self-observation in the social sciences (pp. 3-21). New Brunswick: Transaction Publishers.

Corti, K., Reddy, G., Choi, E., \& Gillespie, A. (2015). The researcher as experimental subject: Using self-experimentation to access experiences, understand social phenomena, and stimulate reflexivity. Integrative Psychological and Behavioral Science, 49(2), 288-308. 
Dennett, D. C. (2003). Who's on first? Heterophenomenology explained. Journal of Consciousness Studies, 10 (9-10), 19-30.

Dennett, D. C. (2007). Heterophenomenology reconsidered. Phenomenology and the Cognitive Sciences, 6 (1), 247-270.

Gantt, E. E., \& Thayne, J. L. (2013). A conceptual history of self-observation in the phenomenological tradition: Brentano, Husserl, and Heidegger. In J. W. Clegg (Ed.), Selfobservation in the social sciences (pp. 147-171). New Brunswick: Transaction Publishers.

Gould, S. (2013). Multimodal introspection theory. In J. W. Clegg (Ed.), Self-observation in the social sciences (pp. 121-144). New Brunswick: Transaction Publishers.

Gutland, C. (2018). Husserlian phenomenology as a kind of introspection. Frontiers in Psychology, 9, 896.

Heavey, C. L., \& Hurlburt, R. T. (2008). The phenomena of inner experience. Consciousness and Cognition, 17(3), 798-810.

Hume, D. (2007). An enquiry concerning human understanding. Oxford: Oxford University Press.

Hurlburt, R. T. (2018). On investigating inner experience: Contrasting Moore \& Schwitzgebel and Brouwers et al. Consciousness and Cognition, 63, 146-150.

Hurlburt, R. T., \& Heavey, C. L. (2001). Telling what we know: describing inner experience. Trends in Cognitive Sciences, 5(9), 400-403.

Husserl, E. (1970). The crisis of European sciences and transcendental phenomenology: An introduction to phenomenological philosophy. (D. Carr Trans.). Evanson: Northwester University Press.

Husserl, E. (1977). Phenomenological psychology: Lectures, Summer Semester, 1925. (J. Scanlon, Trans.). The Hague, Netherlands: Martinus Nijhoff. 
Husserl, E. (1983). Ideas pertaining to a pure phenomenology and to a phenomenological philosophy. (F. Kersten Trans.). The Hague, Netherlands: Martinus Nijhoff.

Irvine, E. (2012). Old problems with new measures in the science of consciousness. The British Journal for the Philosophy of Science, 63(3), 627-648.

Jopling, D. A. (2011). "Much ado to know myself...": Insight in the talking cures. Annals of the New York Academy of Sciences, 1234(1), 158-167.

Kant, I. (1999). Critique of pure reason. (P. Guyer, \& A. W. Wood, Trans.). Cambridge: Cambridge University Press.

Khalil, E. L. (2017). Making sense of self-deception: Distinguishing self-deception from delusion, moral licensing, cognitive dissonance and other self-distortions. Philosophy, 92(4), 539-563.

Knappik, F. (2017). Bayes and the first person: consciousness of thoughts, inner speech and probabilistic inference. Synthese, 195, 1-28.

Kross, E., Bruehlman-Senecal, E., Park, J., Burson, A., Dougherty, A., Shablack, H., ... \& Ayduk, O. (2014). Self-talk as a regulatory mechanism: How you do it matters. Journal of Personality and Social Psychology, 106(2), 304-324.

Kurt, A., \& Paulhus, D. L. (2008). Moderators of the adaptiveness of self-enhancement: Operationalization, motivational domain, adjustment facet, and evaluator. Journal of Research in Personality, 42(4), 839-853.

Kwan, V. S., John, O. P., Robins, R. W., \& Kuang, L. L. (2008). Conceptualizing and assessing self-enhancement bias: A componential approach. Journal of Personality and Social Psychology, 94(6), 1062-1077.

Morin, A. (2006). Levels of consciousness and self-awareness: A comparison and integration of various neurocognitive views. Consciousness and Cognition, 15(2), 358-371. 
Morin, A., Duhnych, C., \& Racy, F. (2018). Self-reported inner speech use in university students. Applied Cognitive Psychology, 32(3), 376-382.

Nisbett, R. E., \& Wilson, T. D. (1977). Telling more than we know: Verbal reports on mental processes. Psychological Review, 84, 231-259.

Peacocke, C. (2014). The mirror of the world: Subjects, consciousness, and selfconsciousness. Oxford: Oxford University Press.

Peels, R. (2016). The empirical case against introspection. Philosophical Studies, 173(9), 2461-2485.

Petitmengin, C., Remillieux, A., Cahour, B., \& Carter-Thomas, S. (2013). A gap in Nisbett and Wilson's findings? A first-person access to our cognitive processes. Consciousness and Cognition, 22(2), 654-669.

Piccinini, G. (2010). How to improve on heterophenomenology: The self-measurement methodology of first-person data. Journal of Consciousness Studies 17 (3-4), 84-106.

Pickrell, J. E., Bernstein, D. M., \& Loftus, E. F. (2012). Misinformation effect. In R. F. Pohl (Ed.), Cognitive illusions: A handbook of fallacies and biases in thinking, judgment and memory (pp. 357-374). New York: Psychology Press.

Przyrembel, M., \& Singer, T. (2018). Experiencing meditation: Evidence for differential effects of three contemplative mental practices in micro-phenomenological interviews. Consciousness and Cognition, 62, 82-101.

Questienne, L., van Dijck, J. P., \& Gevers, W. (2018). Introspection of subjective feelings is sensitive and specific. Journal of Experimental Psychology: Human Perception and Performance, 44(2), 215-225.

Ramm, B. J. (2018). First-person experiments: A characterisation and defence. Review of Philosophy and Psychology, 9(3) 449-467. 
Ren, X., Wang, T., \& Jarrold, C. (2016). Individual differences in frequency of inner speech: Differential relations with cognitive and non-cognitive factors. Frontiers in Psychology, 7 , 1675.

Reyes, G., \& Sackur, J. (2018). Introspection during short-term memory scanning. Quarterly Journal of Experimental Psychology, 71(10), 2088-2100.

Schwitzgebel, E. (2014). Introspection. Stanford Encyclopedia. Retrieved from https://plato.stanford.edu/entries/introspection/

Skinner, B. F. (1953). Science and human behavior. London: Macmillan Press.

Titchener, E. B. (1980). A textbook of psychology. Delmar, N.Y. : Scholars' Facsimiles \& Reprints.

Wagemann, J., Edelhäuser, F., \& Weger, U. (2018). Outer and inner dimensions of brain and consciousness: Refining and integrating the phenomenal layers. Advances in Cognitive Psychology, 14(4), 167-185.

Wagoner, B. (2013). Language in self-observation. In J. W. Clegg (Ed.), Self-observation in the social sciences (pp. 83-101). New Brunswick: Transaction Publishers.

Ward, A. F., \& Wegner, D. M. (2013). Mind-blanking: When the mind goes away. Frontiers in Psychology, 4, 650.

Weger, U., Meyer, A., \& Wagemann, J. (2016). Exploring the behavioral, experiential, and conceptual dimensions of the self. European Psychologist. 21(3), 180-194.

Weger, U., \& Wagemann, J. (2015). The challenges and opportunities of first-person inquiry in experimental psychology. New Ideas in Psychology, 36, 38-49.

Weger, U., Wagemann, J., \& Meyer, A. (2018a). Introspection in psychology: Its contribution to theory and method in memory research. European Psychologist, 23(3), 206-216.

Weger, U., Wagemann, J., \& Meyer, A. (2018b). Researching mind wandering from a firstperson perspective. Applied Cognitive Psychology, 32(3), 298-306. 
Werning, M. (2010). Descartes discarded? Introspective self-awareness and the problems of transparency and compositionality. Consciousness and Cognition, 19(3), 751-761.

Wilson, T. D., \& Dunn, E. W. (2004). Self-knowledge: Its limits, value, and potential for improvement. Annual Review of Psychology, 55, 493-518.

Ziegler R., \& Weger, U. (2018a). First-person experiments in thinking. European Psychologist, 23(3), 189-205.

Ziegler, R., \& Weger, U. (2018b). Exploring conceptual thinking and pure concepts from a first person perspective. Phenomenology and the Cognitive Sciences, 1-26. (first online)

Zedelius, C. M., Broadway, J. M., \& Schooler, J. W. (2015). Motivating meta-awareness of mind wandering: A way to catch the mind in flight? Consciousness and Cognition, 36, $44-53$. 